Ankara Ecz. Fak. Mec.

5. 19. (1975)
J. Fac. Pharm. Ankara

5. 19. (1975)

\title{
L. cariensis Boiss. Bitkisinin Uçucu Yağı Üzerinde Farmakognozik Araștırmalar
}

Die Pharmakognostische Untersuchungen über das Aetherischen Öl von L. cariensis Boiss.

Nevin TANKER, Engin SAARER ( $\left.{ }^{\circ}\right)$

Yeryüzünde bir çok ülkede özellikle Akdeniz memleketlerinde yaygın olarak bulunan Lavandula türlerine (Labiatae) memleketimizde de İstanbul civarında, Marmara, Ege ve Akdeniz bölgelerinde, yabani ya da kültür bitkisi olarak rastlanmaktadır $(1,2,3)$.

Bugün birçok farmakopede kayıtlı olan ve Lavandula türlerinden elde edilen droglar, özellikle Oleum Lavandulae, etkileri çok eskidenberi araştırılan ve çeșitli amaçlarla kullanılan droglar arasındadır $(4,5,6,7,8)$. Memleketimizde oldukça geniş bir yayılıș alanı gösteren $(1,9)$ Lavandula cariensis'ten elde edilecek uçucu yağdan, gerek eczacılık gerekse parfümeri alaninda yararlanıp yararlanılamıyacağını saptamak amacıyla, bu uçucu yağı, araştırmamıza konu olarak seçtik.

MATERYAL ve YÖNTEM

Üzerinde çalıștığımız uçucu yağ, Gemlik'in (Bursa) Karacaali köyü civarından, mayıs 1970, haziran 1971 ve nisan 1972 senelerinde, henüz tamamen çiçek açmadan toplanan Lavandula cariensis Boiss. bitkisinden elde edilmiștir.

Toplanan bitki 5 gün gölgede kurutulduktan sonra odunsu k1sımları ayrılmış, yaprak ve çiçekleri parçalanarak endüstri tipi bir imbik yardımıla subuharı distilasyonuna tabi tutulmuștur. Distilasyon suyundan ayrıldıktan sonra susuz $\mathrm{Na}_{2} \mathrm{SO}_{4}$ ile kurutulan uçucu yağ, sarı renklidir, keskin ve ferahlatıc bir kokuya sahip olup, lezzeti acıdır.

Redaksiyona verildiği tarih : 19 Şubat 1975

(*) Farmakognozi Kürsüsü, Eczacllık Fakültesi, Ankara Üniversitesi 
Elde edilen uçucu yağın analizi için uygulanan yöntemler şunlardir :

1) Miktar tayini :

a - Uçucu yağın volümetrik ve gravimetrik yöntemlerle miktar tayini

b - Uçucu yağın bileşiğinde bulunan maddelerin, gaz kromatogramlarından yararlanarak, planimetri yöntemi ile miktar tayini.

2) Uçucu yağın fiziksel ve kimyasal özelliklerinin saptanması ve alınan sonuçların, kromatografi yoluyla yapılan kalitatif ve kantitatif araștırmalarla karșılaștırılması.

3) Uçucu yağın fraksiyonlanması :

a - Fraksiyonlu kristallendirme,

b - Fraksiyonlu distilasyon,

c - Ince tabaka kromatografisi yardımıyla fraksiyonların saptanmasi,

d - Kolon kromatografisi yardımıyla fraksiyonlara ayırma,

e - Gaz kromatografisi yardımıyla fraksiyonlama ve uçucu yağda bulunan maddelerin saptanması.

4) Fraksiyonlarda saptanan bașlıca maddelerin teşhislerinin kesinleştirilmesi :

a - Türevlerinin hazırlanması ve bu türevlerin fiziksel özeliklerinin saptanması,

b - IR Spektrumları.

$$
\text { B U L G U L A R }
$$

Uçucu yağın miktar tayini, volumetrik ve gravimetrik yöntemlerden yararlanılarak yapıldı. Bulunan uçucu yağ miktarları tablo I de gösterilmiștir :

Tablo 1. L. cariensis'te uçucu yağ verimi.

\begin{tabular}{lcc}
\hline & $\begin{array}{c}\text { Çiçeklerdeki } \\
\text { uçucu yağ miktarı } \\
\%\end{array}$ & $\begin{array}{c}\text { Yapraklardaki } \\
\text { uçucu yağ miktarı } \\
\%\end{array}$ \\
\cline { 2 - 3 } $\begin{array}{l}\text { Volumetrik yöntem } \\
\text { Gravimetrik yöntem }\end{array}$ & 2.4 & 1.2 \\
\hline
\end{tabular}


Uçucu yağın saptanan fiziko-kimyasal özelikleri tablo II de görülmektedir.

Tablo II. L. cariensis'ten elde edilen uçucu yağın fiziko-kimyasal özellikleri.

\begin{tabular}{|c|c|}
\hline Yoğunluk, $20^{\circ} \mathrm{C}$ & 0.9271 \\
\hline Optik çevirme & $+42-45^{\circ}$ \\
\hline Kırılma indisi & 1.4725 \\
\hline Etanolde çözünürlük & $\begin{array}{l}1 \text { kısım uçucu yağ } 0.5 \text { kısım } 70^{\circ} \text { lik } \\
\text { qlkolde berrak olarak çözünür. }\end{array}$ \\
\hline Asitlik indisi & 18.3 \\
\hline Asitlik sayısı & 32.7 \\
\hline Sabunlașma indisi & 45.8 \\
\hline Ester indisi & 27.5 \\
\hline Asetil indisi & 83.2 \\
\hline $\begin{array}{r}\text { Ester miktarı } \begin{array}{r}\left(\mathrm{C}_{12} \mathrm{H}_{20} \mathrm{O}_{2} \text { üzerinden }\right. \\
\text { hesaplanmıș })\end{array}\end{array}$ & $\% \quad 9.6$ \\
\hline 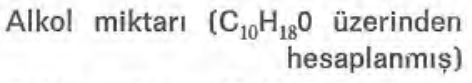 & $\% \quad 15.3$ \\
\hline $\begin{array}{r}\text { Keton miktarı }\left(\mathrm{C}_{10} \mathrm{H}_{16} 0 \text { üzerinden }\right. \\
\text { hesaplanmıș })\end{array}$ & $\% 48.3$ \\
\hline
\end{tabular}

Uçucu yağın bileşimindeki başlıca maddelerin tanımı ve elde ediliși için ince tabaka, gaz ve kolon kromatografisi yöntemlerinden yararlanıldi.

Ince tabaka kromatografi yönteminin uygulanmasında "Kieselgel G, Merck» ile kaplanmış cam plaklardan yararlanıldı. Uçucu yağın bileşimindeki maddelerin ayrılması için hekzan: etil asetat (85: 15) en uygun sistem olarak saptandı. Revelatör olarak antimon III klorür'ün kloroformdaki doymuş çözeltisi ve keton gruplarının teşhisi için de 2.4 - DNPH kullanıldı. Lekeler gün ıșığı ve $\mathrm{UV}_{366}$ da incelendi.

Yöntemin uygulanması sonucu, uçucu yağda o leke saptandı. Lekeler, bilinen saf maddelerin verdiği lekelerle karşılaştırılarak bunların, kâfur, fenkon, borneol, linalol, sineol ve hidrokarbonlara ait olduğu bulundu. Kromatogram 1 ve 2 ile tablo III'te elde edilen lekeler ve $\mathrm{Rf}$ değerleri gösterilmektedir. 


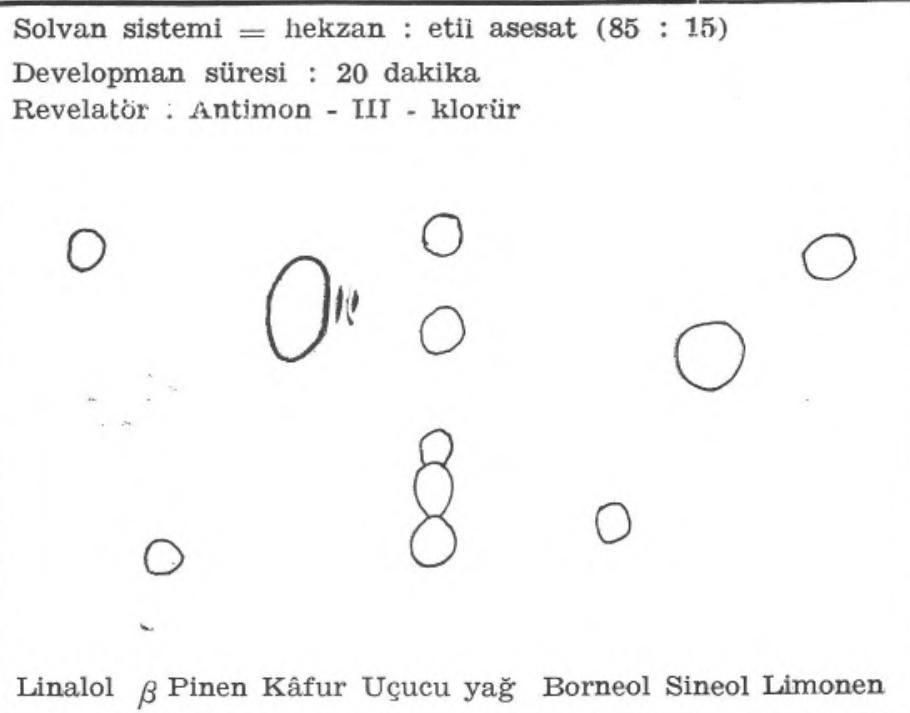

Krom. 1 - L. cariensis uçucu yağındaki maddelerin, ince tabaka kromatografisinde, standartlarla karșılaştırılması.

Solvan : hekzan : etli asetat $(85: 15)$

Developman süresi : 20 dakika

Revelatör 2,4 - DNPH

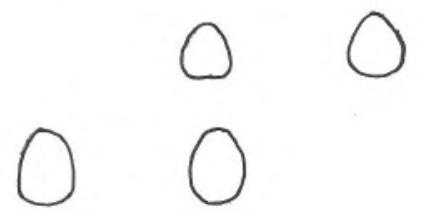

Kâfur Uçucu yağ Fenkon

Krom. 2 - L. cariensis uçucu yağında fenkon ve kâfur'a ait lekelerin saptanması. 
Tablo III. Kromatogram 1 ve 2 ye göre hesaplanan Rf değerleri.

\begin{tabular}{lcc}
\hline & $\begin{array}{c}\text { Standartların } \\
\text { Rf değerleri }\end{array}$ & $\begin{array}{c}\text { Uçucu yağdaki maddelerin } \\
\text { Rf değerleri }\end{array}$ \\
\cline { 2 - 3 } kâfur & 0.21 & 0.21 \\
borneol & 0.29 & 0.29 \\
fenkon & 0.36 & 0.35 \\
linalol & 0.37 & 0.36 \\
sineol & 0.55 & 0.55 \\
limonen & 0.69 & 0.70 hidrokarbonlar \\
$\beta$ - pinen & 0.70 & \\
\hline
\end{tabular}

Her ne kadar uçucu yağda bulunan maddelerin bir kısmını ince tabaka kromatografisi ile teșhis etmek mümkün ise de, terpenik maddeler ince tabakada iyi ayrılmadığı için birbirine yakın olan lekeler vermekte ve bu lekelerin renkleri de birbirine benzemektedir. $\mathrm{Bu}$ nedenle, terpenik yapıdaki maddelerin kesin ayırımı, çok daha hassas olan gaz-likit kromatografi yöntemi ile yapıldı.

Gaz kromatografi ile analizde ucucu yağı teşkil eden maddelerin kromatogramda en iyi şekilde ayrılması içinyöntem farklı şartlarda uygulandı ve analiz 5 ayrı sistemde yürütüldü.

Bunlardan I. sistemde, analiz yüksek derecede $\left(200^{\circ} \mathrm{C}\right)$ yapıldı. II. ve III. sistemlerde $\left(30^{\circ}-50^{\circ} \mathrm{C}\right)$ monoterpenik hidrokarbonların, IV. ve V. sistemlerde $\left(125^{\circ} \mathrm{C}-150^{\circ} \mathrm{C}\right)$ ise oksijenli bileşiklerin analizi yapıldı. Bu beş sisteme ait şartlar tablo IV de verilmiştir. 
Tablo. IV. L. cariensis'ten elde edilen uçucu yağın gaz kromatografik analizinde yararlanılan sistemler.

\begin{tabular}{|c|c|c|c|c|c|}
\hline & Sistem I & Sistem II & Sistem III & Sistem IV & Sistem V \\
\hline Aparey & Packard 7400 & Packard 409 & Aerograph 1520 & Aerograph 1520 & Packard 409 \\
\hline Dedektör & FID & FID & FID & FID & FID \\
\hline Kolon & $\begin{array}{l}5.5 \mathrm{~mm} \text { çap ve } 2 \mathrm{~m} \\
\text { uzunlukta, cam .. }\end{array}$ & $\begin{array}{l}1.5 \mathrm{~mm} \text { çap ve } 8 \mathrm{~m} \\
\text { Uzunlukta, bakır }\end{array}$ & $\begin{array}{l}1.5 \mathrm{~mm} \text { çap ve } 8 \mathrm{~m} \\
\text { uzunlukta, bakır }\end{array}$ & $\begin{array}{l}1.5 \mathrm{~mm} \text { çap ve } 8 \mathrm{~m} \\
\text { uzunlukta, bakır }\end{array}$ & $\begin{array}{l}1.5 \mathrm{~mm} \text { çap ve } 8 \mathrm{~m} \\
\text { uzunlukta, bakır }\end{array}$ \\
\hline Stasyoner faz & $\begin{array}{l}\% 20 \text { Carbowax } \\
20 \mathrm{M}\end{array}$ & $\begin{array}{l}\% 10 \beta, \beta^{\prime}-\text {-Oxydi } \\
\text { propionitrile }\end{array}$ & $\begin{array}{l}\% 10 \text { Carbowax } \\
1540\end{array}$ & $\begin{array}{l}\% 10 \text { carbowax } \\
1540\end{array}$ & $\% 10$ PEG 20M \\
\hline Adsorban & Chromosorb P & $\begin{array}{l}\text { Chromosorb w } \\
60 / 80 \text { mesh }\end{array}$ & $\begin{array}{l}\text { Chromosorb w } \\
60 / 80 \text { mesh }\end{array}$ & $\begin{array}{l}\text { Chromosorb w } \\
60 / 80 \text { mesh }\end{array}$ & $\begin{array}{l}\text { Chromosorb w } \\
60 / 80 \text { mesh }\end{array}$ \\
\hline Isı & $200^{\circ} \mathrm{C}$ izotermal & $30^{\circ} \mathrm{C}$ izotermal & $65^{\circ} \mathrm{C}$ izotermal & $125^{\circ} \mathrm{C}$ izotermal & $150^{\circ} \mathrm{C}$ izotermal \\
\hline Dedektör Isısı & $210^{\circ} \mathrm{C}$ & $180^{\circ} \mathrm{C}$ & $225^{\circ} \mathrm{C}$ & $240^{\circ} \mathrm{C}$ & $200^{\circ} \mathrm{C}$ \\
\hline Enjektör Isısı & $210^{\circ} \mathrm{C}$ & $190^{\circ} \mathrm{C}$ & $200^{\circ} \mathrm{C}$ & $197^{\circ} \mathrm{C}$ & $197^{\circ} \mathrm{C}$ \\
\hline Taşıyıcı gaz & Azot & Azot & Azot & Azot & Azot \\
\hline $\mathrm{H}_{2}$ geçiş hızı & $40 \mathrm{ml} / \mathrm{dak}$ & $25 \mathrm{ml} / \mathrm{dak}$ & $30-35 \mathrm{ml} / \mathrm{dak}$ & $20 \mathrm{ml} / \mathrm{dak}$ & $25 \mathrm{ml} / \mathrm{dak}$ \\
\hline
\end{tabular}


I. sistem ile uçucu yağda 13 madde saptandı. Bunlardan teşhis ettiklerimiz, $\alpha$-pinen, limonen, sineol, fenkon, linalol, kâfur ve borneol'dür.

I. sistemde yüksek derecede $\left(200^{\circ} \mathrm{C}\right)$ yaptığımız analiz sırasında, alçak derecede kaynayan monoterpenik hidrokarbonlar yönünden hataya düşmemizi önlemek ve sadece bu sistemi uygulayarak teșhis edemediğimiz maddelerin tanınmasını sağlamak üzere diğer dört sistem uyguland. Piklerin isimlendirilmesi, retensiyon zamanlarının tayini ve bulunan değerlerin standart madde ve uçucu yağlara ait değerlerle karșılaștırılması ile yapıldı.

Uçucu yağlar yapıları karışık bileşiklerdir. Fakat uçucu yağ içindeki maddeleri, alçak derecede kaynayan monoterpenik hidrokarbonlar ve yüksek derecede kaynayan oksijenli bileşikler olmak üzere 2 büyük grupta toplamak mümkündür (10) :

Monoterpenik hidrokarbonlarun teşhisi : Sistem II ve III, alçak derecede kaynayan monoterpenik hidrokarbonların teşhisi için uygulandı. Literatür'e göre uçucu yağ analizlerinde uzun kolonların kullanilması daha iyi netice vermektedir (11). Bu esasa dayanarak, değişik stasyoner fazlar ile farklı ısı ve basınçta uzun kolonlar sayesinde bu grup maddelere ait pikler kesinlikle tespit ve teșhis edilebildi.

Analiz sonucu teşhis edilen monoterpenik hidrokarbonlar, $\alpha$-pinen, kamfen, $\beta$ - pinen, limonen, $\mathrm{p}$ - simen'dir. Miktarları yönünden önemli olanlar, $\alpha$ - pinen, kamfen ve limonen'dir Bu maddelere ait retensiyon zamanları tablo $\mathrm{V}$ 'de, gaz kromatogramlar ise ileriki sayfalarda verilmiștir (Kromatogram 3,4).

Tablo V. L. cariensis uçucu yağındaki monoterpenik hidrokarbonların $\beta \beta^{\prime}$-oxydipropionitrile ve Carbowax 1540 kolonlarındaki retensiyon zamanlari.

\begin{tabular}{clcc}
\hline (1) $\alpha$ - pinen & $\begin{array}{c}\beta, \beta^{\prime}-\text { Oxydipropionitrile } \\
\text { (sist. II) }\end{array}$ & $\begin{array}{c}\text { Carbowax 1540 } \\
\text { (sist. III) }\end{array}$ \\
(2) kamfen & 3.9 & 4.8 \\
(3) $\beta$ - pinen & 5.9 & 6.3 \\
(4) limonen & 7.3 & 7.9 \\
(101) sineol & 15.0 & 13.3 \\
(5) $\quad$ - simen & 29.7 & 17.1 \\
\hline
\end{tabular}




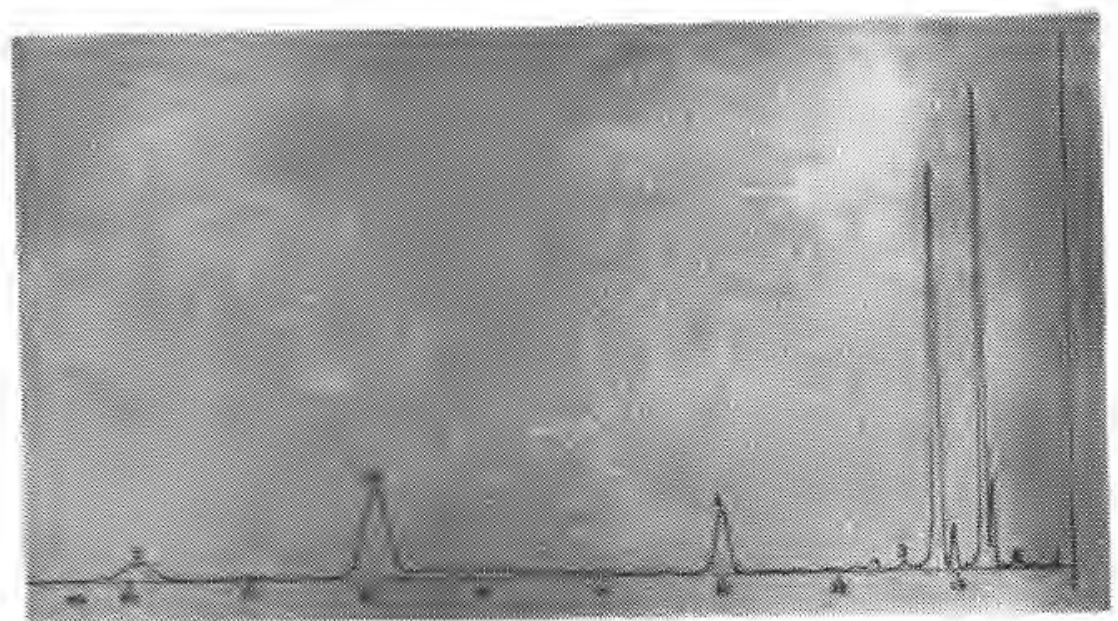

Krom. 3 - L. cariensis uçucu yaḡındaki monoterpenik hidrokarbonların $\beta, \beta$ ' - oxydipropionitrile kolonundaki kromatogrami.

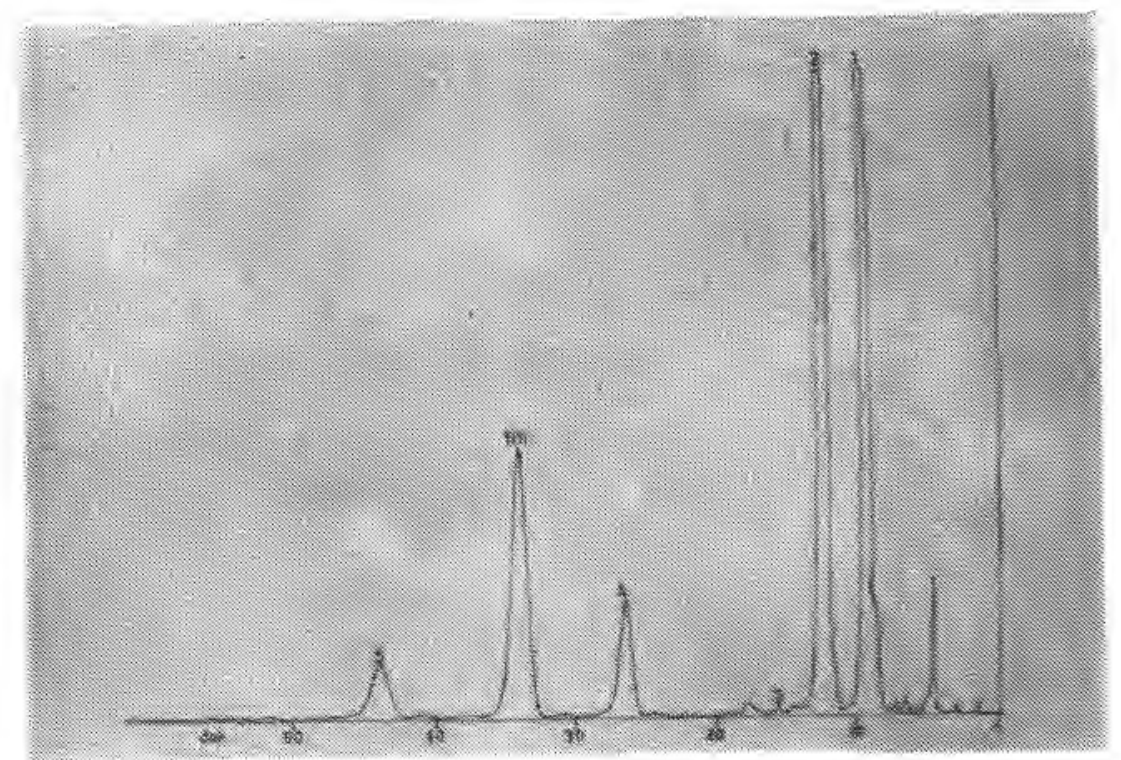

Krom. 4 - L. cariensis uçucu yağındaki monoterpenik hldrokarbonlarin Carbowax 1540 kolonundaki kromatogramı. 
Oksijenli bileșiklerin teșhisi : Yüksek derecede kaynayan oksijenli bileşiklerin teşhisinde sistem IV ve V den yararlanıldı. Bu amaçla uçucu yağa ait kromatogramlarda monoterpenlere ait son pik tespit edilerek, monoterpenlerle oksijenli bileșikler arasındaki sinır belirlendi. Daha sonra standart madde ve uçucu yağların retensiyon zamanlarına göre, piklerin teşhisi yapıldı.

Her iki sistem ile teşhisi yapılan maddeler, sineol, fenkon, linalol, linalil asetat, kâfur, bornil asetat, sitronellol, nerol ve geraniol'dür. Miktarları bakımından önemli olanlar, kâfur, fenkon, geranil asetat ve terpineoldür.

$\mathrm{Bu}$ maddelere ait retensiyon zamanları tablo VI da, gaz kromatogramlar kromatogram 5 ve 6 da görülmektedir.

Tablo VI. L. cariensis uçucu yağındaki oksijenli bileşiklerin Carbowax 1540 ve PEG $20 \mathrm{M}$ kolonlarındaki retensiyon zamanları.

\begin{tabular}{|c|c|c|c|}
\hline & & $\begin{array}{c}\text { Carbowax } 1540 \\
\text { (sist. IV) }\end{array}$ & $\begin{array}{l}\text { PEG 20M } \\
\text { (sist. V) }\end{array}$ \\
\hline (101) & sineol & 3.3 & 3.8 \\
\hline (102) & fenkon & 7.6 & 6.7 \\
\hline (103) & linalol & linalol $+x$ & 8.3 \\
\hline (104) & linalil asetat & 11.8 & 9.2 \\
\hline (105) & kâfur & 13.0 & 10.1 \\
\hline (106) & bornil asetat & 14.2 & 10.7 \\
\hline (107) & terpinen -4 ol & 14.9 & 11.2 \\
\hline (109) & borneol & 19.8 & 15.1 \\
\hline (108) & terpineol & 22.8 & 14.6 \\
\hline (110) & geranil asetat & 29.1 & 18.4 \\
\hline (111) & sitronellol & 30.7 & 19.1 \\
\hline (112) & nerol & 37.1 & 21.8 \\
\hline (113) & geraniol & 44.7 & 24.5 \\
\hline
\end{tabular}




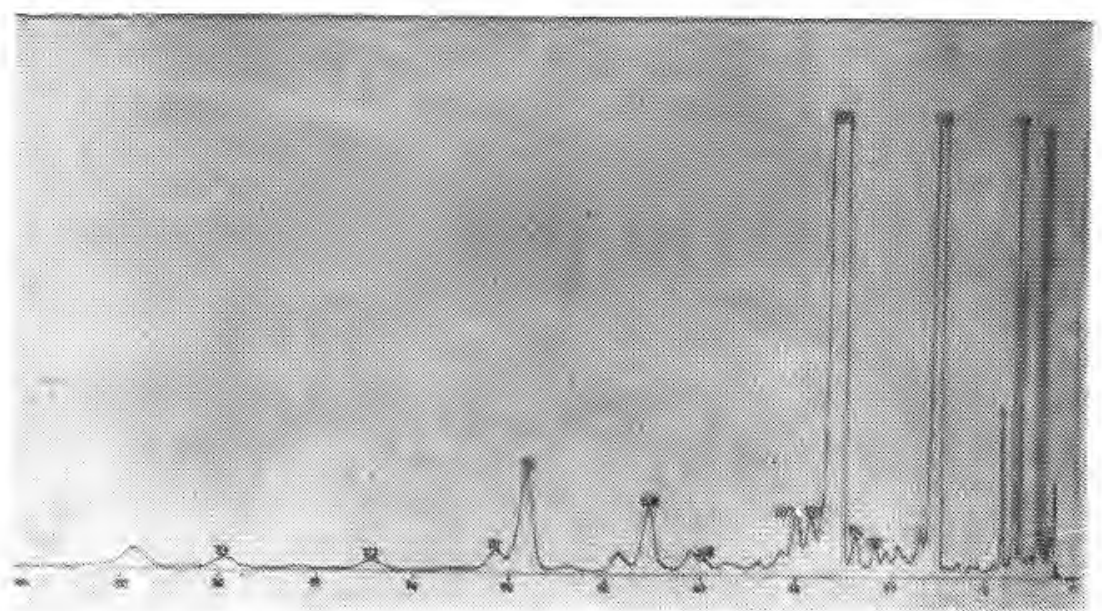

Krom. 5 - L, cariensis uçucu yağındaki oksijenli bileșiklerin Carbowax 1540 kolonundaki kromatogramı.

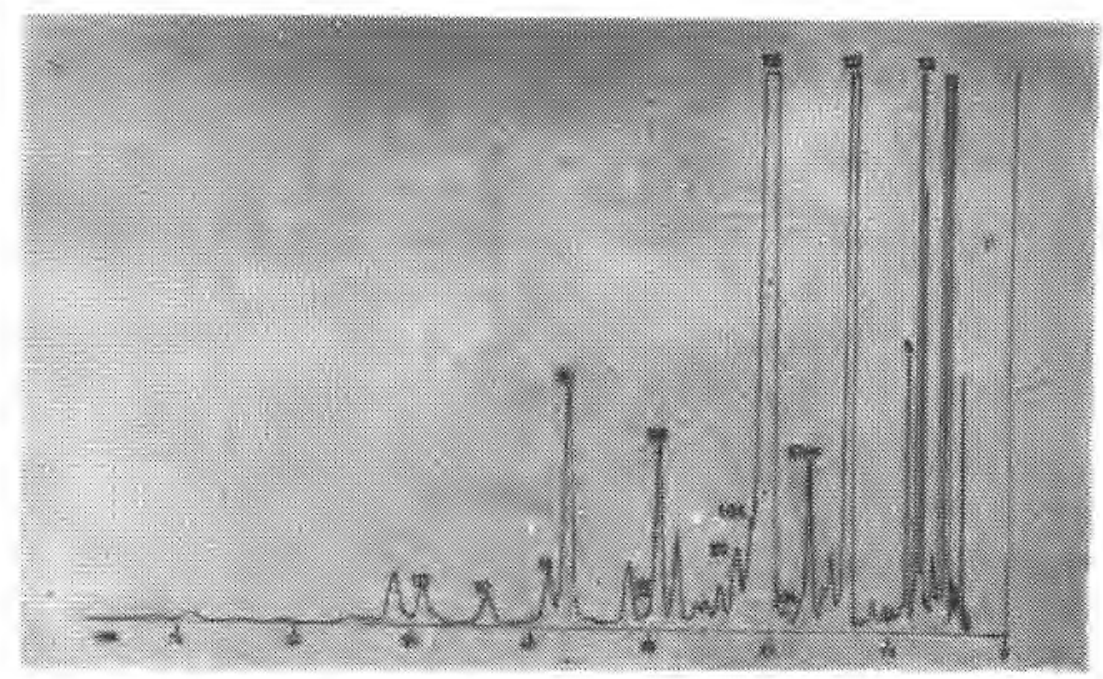

Krom. 6 - L. cariensis uçucu yağındakí oksijenli bileșiklerin PEG 20M kolonundaki kromatogramı. 
Uçucu yağdaki maddelerin teșhisinden sonra, bu maddelerden yüksek oranlarda olanlarnn izolasyonu işlemine geçildi. İzolasyon sırasında maddelerin özelliklerine göre kolon kromatografisi, süblimasyon ve gaz kromatografi yöntemlerinden yararlanıldı.

Kolon kromatografisi ile yapılan analiz sırasında en iyi sonuç "Kieselgel $0.05-0.2 \mathrm{~mm}$ » adsorbanı ve hekzan, etil asetat solvanları ile alınd. Uygulamada $10 \mathrm{~g}$ Kieselgel ile hazırlanan kolona 1 ml uçucu yağ tatbik edildi ve önce monoterpenik hidrokarbonları elde etmek amaciyla hekzanla, daha sonra oksijenli bileșikleri elde etmek üzere, etil asetat ile elüe edildi. Ahnan $3 \mathrm{er} \mathrm{ml}$ lik fraksiyonların, maddelerin elde ediliș sırası gözlenmek üzere gaz kromatogramları alındi.

Uçucu yă̆ bileșimindeki terpenik maddelerin çözünürlükleri birbirine çok yakın olduğundan kolon kromatografisi ile 5. fraksiyonda oldukça saf halde $\alpha$-pinen, 22 ve 23 . fraksiyonlarda çok az miktarda fenkon ve 24,25 ve 26 . fraksiyonlarda fenkon-kâfur karıșımları elde edilebildi.

Kâfur'un izolasyonu ve tanımı : Uçucu yağdan süblimasyon yoluyla elde edilen kâfur yanında fenkon bulunmaktadır.

Kolon kromatografisi yöntemi ile elde edilen kâfur da fenkon ile karıșım halindedir.

Kâfur - fenkon karıșımlarında kâfur'u teşhis etmek üzere süblimasyonla elde edilen kristallerden hareketle kâfur'un semirkarbazonu hazirlandi.

Elde edilen semirkarbazon kristallerinin ergime noktas $1233^{\circ} \mathrm{C}$ olarak saptandı. Bu değer kâfur'un semirkarbazonunun literatür. de verilen değerine uymaktadır (12).

Kâfur'u saf halde elde etmek amaciyla, uçucu yağda preparatif olarak çalışıldı. Gaz kromatogramda kâfur pikine ait olan fraksiyon toplandı. Bu fraksiyon kristallerden ibaretti. Kristaller uygun çözücüde çözülerek IR spektrumu alındı. Bu spektrumun standart kâfur spektrumu ile identik olduğu saptandı (Spektrum I). 


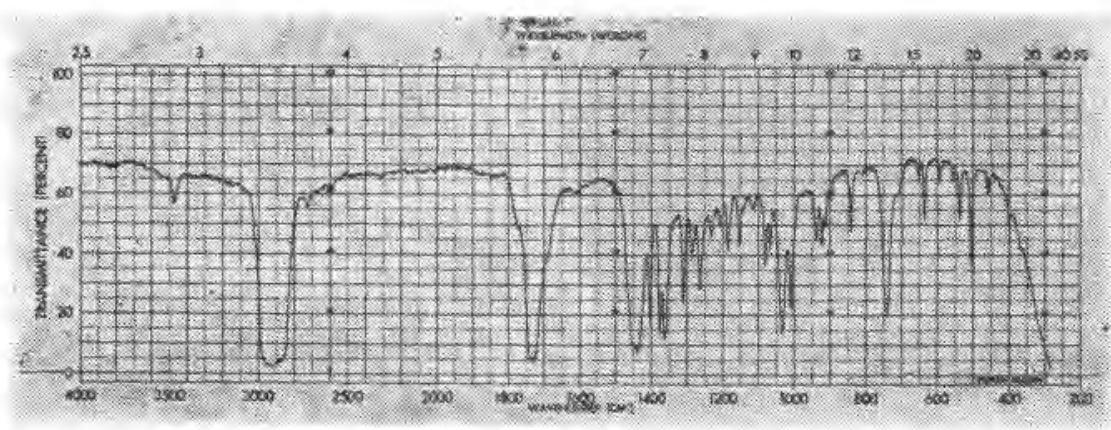

Spektr. I - Kâfur'un IR spektrumu.

Fenkon'un izolasyonu ve tanımı : Uçucu yağın oksijenli bilesiklerinin kolonda etil asetat ile elüsyonu sirasında, 22, ve 23. fraksiyonlarin az miktarda fenkon, 24. fraksiyonun ise fenkon yaninda bir miktar da kâfur ihtiva ettiği görülmüștür.

$\mathrm{Bu}$ iki maddenin çözünürlüklerinin birbirine çok yakm olduğu düșuinülerek daha iyi bir ayırım sağlamak amacıyla uçucu yağın fraksiyonlu distilasyonu yapıldı ve literatüre göre fenkon'un kaynama noktası olan $190-195^{\circ} \mathrm{C}$ de geçen fraksiyon toplandı (13). Bu fraksiyonun, gaz kromatografa uygulanması ile, hemen hemen eșit miktarda fenkon ve kâfur ihtiva ettiği görüldùi. Fenkon'un oksitleyici maddeler karşısında dayanıklıhı̆ı gözönünde bulundurularak toplanan fraksiyon önce $\mathrm{KMnO}_{4}$, daha sonra $\mathrm{HNO}_{3}$ ile oksitlendi.

Oksitlemelerden sonra distilasyon ile toplanan fenkon, yine bir miktar kâfur ihtiva ediyordu. Bu kâfur'u ayırmak için de kâfurun kolayca semirkarbazon teșkil etme özelliğinden yararlanıldı. Kâfur'un semirkarbazonu 3 gün sonra kristallendi. Kristaller çözeltiden ayrildıktan sonra fenkon'un semirkarbazonu hazırland. Literatïre göre kâfur'un semirkarbazonu birkaç gün içinde çöktüğ̈i halde fenkon'un semikarbazonu 2 hafta gibi uzun bir süre sonunda meydana gelmektedir. Fenkonun semirkarbazonunun elde edilmesi için kullanılan çözeltide 2,3 ve 4. günlerde kâfur'un semikarbazonuna ait kristaller aynldr. Bu kristaller alındıktan sonra çözeltide onaltıncı gün yeniden kristallenmeler bașladı. Bu kristaller temizlenerek ergime noktasına bakıld $1,182^{\circ} \mathrm{C}$ bulundu. Bu değer, literatürde fenkon semikarbazon için verilen değere uymaktadır. (13). 
Fenkon'un saf halde elde etmek üzere bir defa da preparatif gaz kromatografi yöntemi uygulandı. Bir mikrotüp içine toplanan maddenin IR spektrumu alındı. Bunun saf fenkon'un IR spektrumu ile aynı olduğu saptandi (14) (Spektrum II).

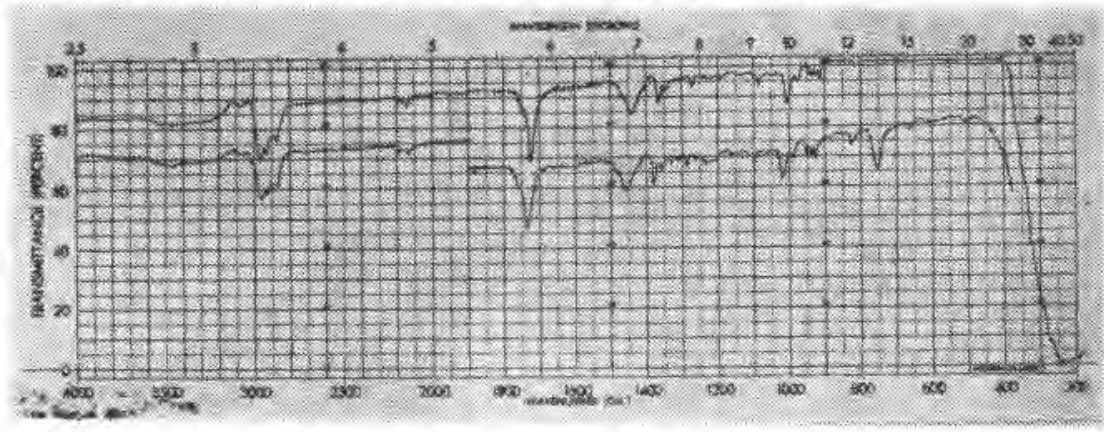

Spektr. II - Fenkon'un IR spektrumu.

$\alpha$ - Pinen'in izolasyonu ve tanımu : Kolon kromatografisi yönteminde hekzan kullaniarak elde edilen terpenik hidrokarbon fraksiyonlarından beşinci fraksiyonun $\alpha$-pinen ihtiva ettiği, bu fraksiyonda, $\alpha$-pinen nitrozoklorürü hazırlanarak (15) saptand.. Elde edilen nitrozoklorïr kristalleri temizledikten sonra ergime noktası tayin edildi: $112^{\circ} \mathrm{C}$, bu değer $\alpha$-pinen'in nitrozoklorürü için literatürde verilen değere uymaktadir (11).

-pinen'i saf halde elde etmek üzere preparatif olarak çalıșıldı. Bir mikrotüpte toplanan maddenin IR spektrumu alınd. Bu spektrumun saf $\alpha$-pinen'in IR spektrumu ile aynı olduğu saptandi (14) (Stepktrum III).

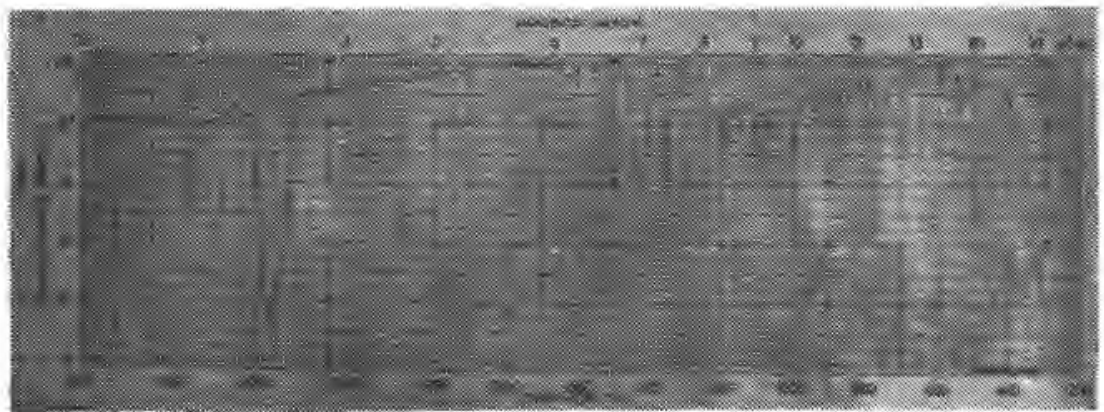

Spektr. III $-\alpha$-pinen'in IR spektrumu. 
Miktar tayini : Uçucu yağda saptanan maddelerin miktaıı gaz kromatogramlarından yararlanılarak ve planimetre yöntemi ile tayin edildi. $\mathrm{Bu}$ amaçla önce hidrokarbonların ve oksijenli bileșiklerin uçucu yağ içindeki bulunuş yüzdesi hesaplandı. Daha sonra bu gruplardaki her bir maddenin, grubu içindeki bulunuş yüzdesi hesaplandı. Bulunan değerler Tablo VII'de verilmiștir.

Tablo VII. Uçucu yağda bulunan maddelerin \% miktarları.

\begin{tabular}{|c|c|c|c|c|c|c|c|}
\hline $\begin{array}{l}\text { Pik } \\
\text { No. }\end{array}$ & Hidrokarbonlar & $\%$ & 23.6 & $\begin{array}{l}\text { Pik } \\
\text { No. }\end{array}$ & Oksijenli bileșikler & $\% 76.3$ & Total \\
\hline 2 & kamfen & & 30.4 & & & & 7.1 \\
\hline 1 & $\alpha$-pinen & & 27.7 & & & & 6.5 \\
\hline 101 & slneol & & 19.8 & & & & 4.7 \\
\hline 4 & limonen & & 6.6 & & & & 1.6 \\
\hline 5 & p-simen & & 5.1 & & & & 1.2 \\
\hline \multirow[t]{16}{*}{3} & $\beta$-pinen & & 0.6 & & & & 0.1 \\
\hline & bilinmeyen & & 9.6 & & & & 2.3 \\
\hline & & & & 105 & kâfur & 39.3 & 30.0 \\
\hline & & & & 102 & fenkon & 23.6 & 18.0 \\
\hline & & & & 110 & geranil asetat & 8.1 & 6.2 \\
\hline & & & & 101 & sineol & 7.0 & 5.3 \\
\hline & & & & 108 & terpineol & 5.4 & 4.1 \\
\hline & & & & 106 & bornil asetat & 3.2 & 2.4 \\
\hline & & & & 107 & terpinen-4-ol & 3.0 & 2.3 \\
\hline & & & & 104 & linalil asetat & 1.8 & 1.4 \\
\hline & & & & 111 & sitronellol & 1.6 & 1.2 \\
\hline & & & & 113 & geraniol & 1.5 & 1.1 \\
\hline & & & & 112 & nerol & 1.1 & 0.8 \\
\hline & & & & 103 & linalol & 0.8 & 0.6 \\
\hline & & & & 109 & borneol & 0.6 & 0.5 \\
\hline & & & & & bilinmeyen & 2.6 & 2 \\
\hline
\end{tabular}

Ưzerinde araştırma yaptığımız Lavandula cariensis bitkisinin yaprakları \% 1.3, çiçekleri ise \% 2.7 oranında uçucu yağ taşımaktadır. Uçucu yağ elde edilen Lavandula türlerinde bu değer genellikle \% 1 civarındadır (3). Buna göre $L$. cariensis in taşıdığı yağ miktarı, uçucu yağ elde edilen Lavandula türlerindekinden fazladır. 
Uçucu yağın saptanan fiziko-kimyasal özellikleri yönünden ticarette çok rastlanan lavanta uçucu yağı, Lavadin ve Aspik esansı ile karșılaștırılması tablo VIII'de yapilmıștır.

Tablo VIII. L. cariensis'ten elde edillen uçucu yağın, lavanta uçucu yağı, Lavandin, ve Aspík esansı ile fiziko-kimyasal özellikleri yönünden karșılaștırılması.

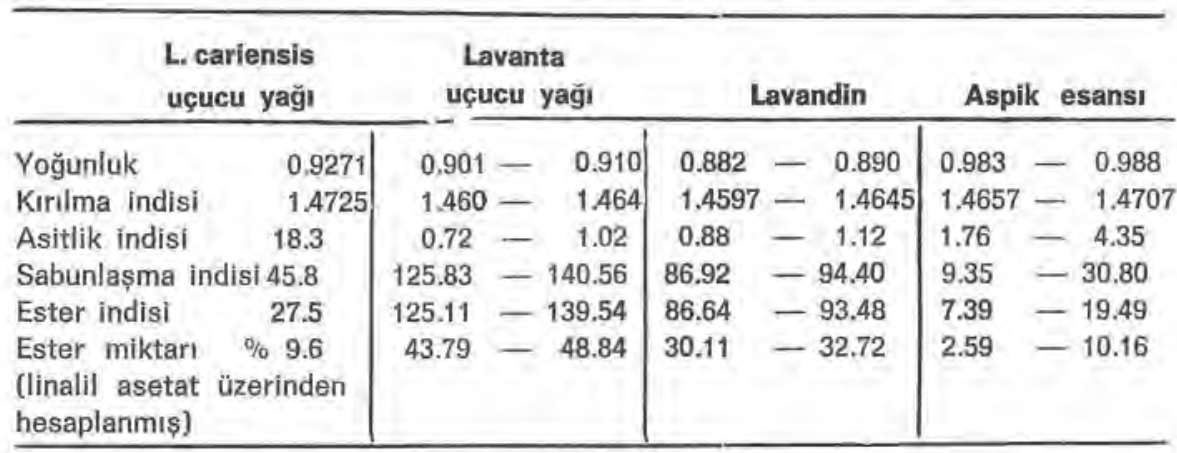

Tablo incelendiğinde uçucu yağın yoğunluk, kırılma indisi, sabunlaşma indisi ve ester miktarı bakımından lavanta uçucu yağı ve Lavandin'den çok Aspik esansına benzer olduğu görülmektedir. Asitlik indisinde görülen fazlalık ortamda bulunabilecek serbest asitlerden ileri gelebilir. Ancak asitlik indisi bitkinin toplanış zamanına, distilasyon şartlarına ve yağın bekleme süresine göre değișmektedir.

Elde ettiğimiz uçucu yağın IR spektrumu ile adı geçen uçucu yağların IR spektrumları incelenerek, bileşimlerinde bulunan gruplar açısından bir karșılaştırma yapılabilir (Spektrum IV,V,VI,VII).

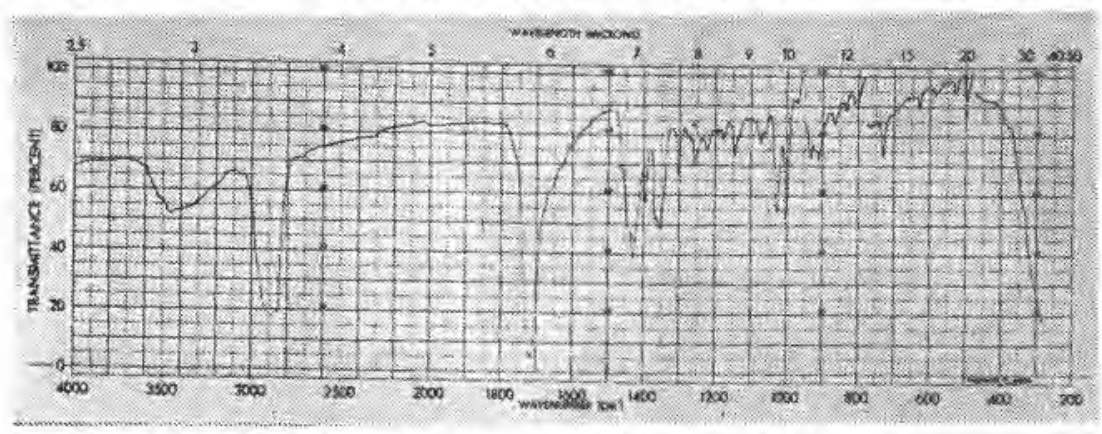

Spektr. IV - L. cariensis uçucu yag̈ının IR spektrumu. 


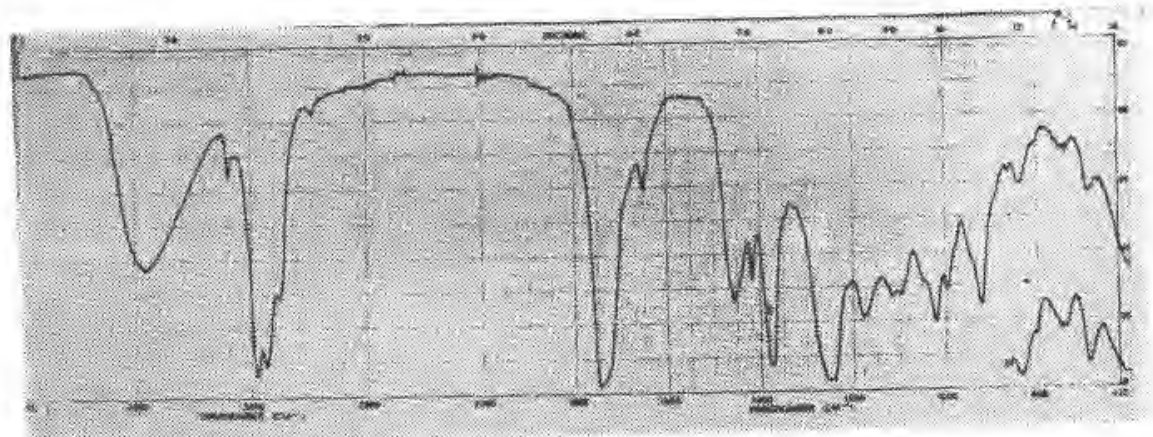

Spektr. V - Lavanta uçucu yağının IR spektrumu.

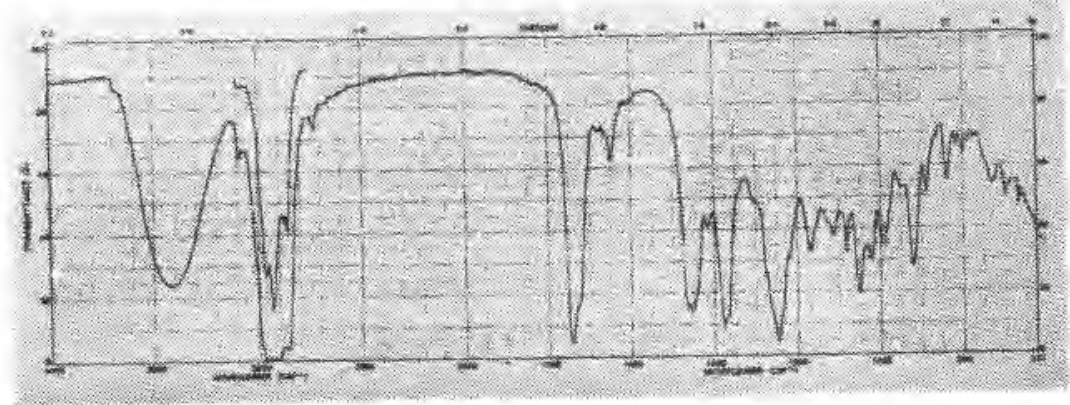

Spektr. VI - Lavandin'in If spektrumu.

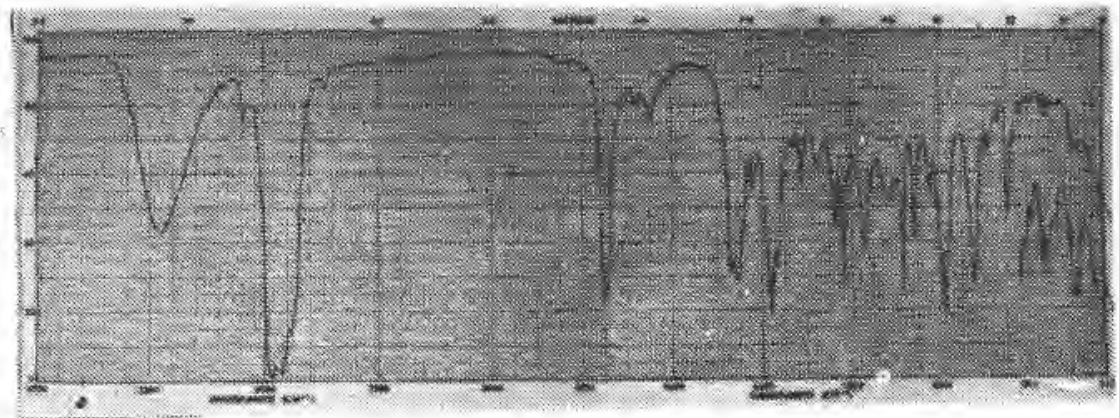

Spektr. VII - Aspik esansinin IR spektrumu.

Spektrumlarda $3430 \mathrm{~cm}^{-1}$ deki bant, serbest alkollerin varlığımı göstermektedir (16). Lavanta uçucu yağı, Lavandin ve Aspik esansunda bu bantın çok büyük olmasına karşılık, L. cariensis uçucu yağın- 
da küçüktür. Bu durum $\boldsymbol{L}$. cariensis uçucu yağındaki serbest alkol miktarının diğer uçucu yağlardakinden az olduğunu doğrular.

$1720 \mathrm{~cm}^{-1}$ de yer alan ve $\mathrm{C}=\mathrm{O}$ grubuna ait olan bantin $L$. $c a^{-}$ rieinsis uçucu yağında çok belirli bir şekilde görülmesine karșılık, diğer uçucu yağlarda bu bölgede kesin bir bant görülmemektedir. Buna göre $L$. cariensis in uçucu yağındaki keton miktarı, diğerlerinden belirli bir fark göstermektedir. Diğer uçucu yağlarda bulunmas1 muhtemel olan az miktarda ketona ait bantın ester bantlar: ile karışmış olabileceği de düşünülebilir.

1740,1235 ve $1025 \mathrm{~cm}^{-1}$ de görülen bantlar karakteristik ester bantlarıdır. Spektrumlar incelendiğinde, bu bantların lavanta uçucu yağı ve Lavandinde büyük, Aspik esansı ve $L$. cariensis uçucu yağında ise küçük olduğu görülmektedir. Buna göre lavanta uçucu ya$\breve{g}_{1}$ ve Lavandin, Aspik esansı ve $L$. cariensis uçucu yağına göre fazla miktarda asetik asit esterleri ihtiva etmektedirler.

Titrimetrik ve gaz kromatografik miktar tayinlerinde bulunan alkol, keton ve ester miktarları da bu sonuçları doğrulamaktadır.

L. cariensis uçucu yağının IR spektrumunda: 3468, 1421, 1303, 1048,855 ve $742 \mathrm{~cm}^{-1}$ de görülen bantlar kâfur bantları; 3460,1748 , $1388,1365,1022,999$ ve $941 \mathrm{~cm}^{-1}$ de görülen bantlar ise fenkon bantlaridir (4).

Lavandula cariensis uçucu yağında teşhis ettiğimiz terpenik maddeler; $\alpha$-pinen, kamfen, $\beta$-pinen, limonen, sineol, $p$-simen, fenkon, linalol, linalil asetat, kâfur, bornil asetat, terpinen-4-ol, borneol, terpineol, geranil asetat, sitronellol, nerol ve geraniol'dür.

Uçucu yağın, lavanta uçucu yağı, Lavandin ve Aspik esansı ile kimyasal bileşim yönünden karşılaștırılması tablo IX da yapılmıştir. 
Tablo IX. L. cariensis uçucu yağının, lavanta uçucu yağı, Lavandin ve Aspik esansı ile kimyasal bileșimi yönünden karșılaștırılması.

\begin{tabular}{|c|c|c|c|c|}
\hline & $\begin{array}{c}\text { Lavanta } \\
\text { uçucu yağı } \\
\%\end{array}$ & $\begin{array}{c}\text { Lavandin } \\
\%\end{array}$ & $\begin{array}{c}\text { Aspik } \\
\text { esansı } \\
\%\end{array}$ & $\begin{array}{c}\text { L. cariensis } \\
\text { uçucu yağı } \\
\%\end{array}$ \\
\hline kâfur & 0.2 & 7 & 14 & 30 \\
\hline fenkon & - & - & - & 18 \\
\hline sitronellol & $?$ & $?$ & $?$ & 1.2 \\
\hline sineol & 1 & 7.6 & $36-47$ & 5.3 \\
\hline linalil asetat & 38 & 19 & 0.3 & 1.4 \\
\hline geranil asetat & 1.8 & 0.3 & $?$ & 6.2 \\
\hline \multirow{2}{*}{$\left.\begin{array}{l}\alpha \text { - pinen } \\
\text { kamfen } \\
\text { terpineol }\end{array}\right\}$} & eser & eser & eser & 7 \\
\hline & 1.8 & 0.5 & $?$ & 4.1 \\
\hline
\end{tabular}

Buna göre, $L$. cariensis uçucu yağı diğer Lavandula türlerinden elde edilen ticari uçucu yağlardan farklı olarak linalol ve linalil asetat'ı ancak çok az miktarda ihtiva eder, buna karşılık kâfur ve fenkon bakımından zengin bir uçucu yağdır.

L. cariensis uçucu yağ nın büyük bir kısmını teșkil eden kâfur, etkileri ve özellikle antisepıik etkisi eskidenberi bilinen bir maddedir. Dahilen irritan ve karminatiftir. Hafif ekspektoran olarak ve gribe karşı kullanılır. Haricen rubefiyan ve hafif analjezik etkisi vardir ve linimetler halinde fibrozit, nevralji ve benzeri durumlarda kullanilır.

Uçucu yağda önemli miktarda bulunan fenkon da kâfur'a benzer kokulu ve benzer etkili bir maddedir. Uçucu yağin bileșiminde bir miktar da sineol bulunmaktadir.

$\mathrm{Bu}$ özeliklerinden dolayı, $L$. cariensis uçucu yağının eczacılıkta kullanılması, ayrıca bu yağdan kâfur kaynağı olarak yararlanılması mümkün görülmektedir.

\section{Ö ZET}

Anadolu'da yaygin olarak bulunan Lavandula cariensis Boiss. bitkisinin uçucu yağı üzerinde yaptığımız çalıșmalar sonunda, bitkideki uçucu yağ miktarı, uçucu yağın fiziko - kimyasal özelikleri ve kimyasal yapısı açıklanmış oldu. 
L. cariensis bitkisinin uçucu yağ verimi; çiçeklerde \% 2.7, yapraklarda \% 1.3 olarak saptand. Elde edilen uşucu yağın yoğunluğu 0.9271 , optik çevirmesi $+42-45^{\circ}$, kırılma indisi $1.4725,70^{\circ}$ lik etanoldeki çözünürlüğü $1 / 0.5 \mathrm{k} 1 \mathrm{sım}$, asitlik indisi 18.3 , asitlik sayısı 32.7 , sabunlașma indisi 45.8 , ester indisi 27.5 ve asetil indisi $83.2 \mathrm{dir}$. Uçucu yağdaki ester miktan (linalil asetat üzerinden) \% 9.6, alkol miktarı (linalol üzerinden) \% 13,3 keton miktarı ise (kâfur üzerinden) \% 48.3 bulundu.

Uçucu yağın, ince tabaka ve beş ayrı sistemde yürütülen gaz kromatografi yöntemlerinden yararlanarak yapılan analizi sonucunda uçucu yağın bileșiminde, monoterpenik hidrokarbonlardan; kamfen $(\% 7,1), \alpha$ - pinen $(\% 6.5)$, limonen ( $\% 1.6), p-\operatorname{simen}(\% 1.2)$, $\beta$ - pinen (\% 0.1) in varlığı, oksijenli maddelerden; kâfur (\% 30), fenkon ( $\% 18)$, geranil asetat $(\% 6.2)$, sineol ( $\% 5.3)$, terpineol ( $\%$ $4.1)$, bornil asetat $(\% 2.4)$, terpinen - 4 . ol $(\% 2.3)$, linalil asetat $(\%$ $1.4)$, sitronellol ( $\% 1.2)$, geraniol ( $\% 1.1)$, nerol ( $\% 0.8)$, linalol $(\%$ $0.6)$, borneol (\% 0.5) un varlığ ları bakımından önemli olanlar, kâfur, fenkon, geranil asetat, kamfen ve $\alpha$ - pinen'dir.

Gaz kromatogramlardan yararlanarak, planimetre yöntemi ile hidrokarbon ve oksijenli bileşikler gruplarının ve bu gruplardaki maddelerin \% miktarlan hesapland.

\section{ZUSAMMENFASSUNG}

In der vorliegenden Arbeit haben wir die physikalische Eigenschaften und chemische Zusammensetzung des aetherischen Öls von Lavandula cariensis Boiss, untersucht, dass wir es durch Damipfdestillation aus den Blüten und Blacttern von der Pflanze gewonnen haben.

Die Ausbeute an Öl betraegt bei Blüten bis $2.7 \%$, bei den Blaettern bis $1.3 \%$. Das Öl ist gelb und hat einen campherartigen $\mathrm{Ge}$ ruch. Es hat folgende Konstanten: $d_{20}=0.9271,(\alpha)_{\mathfrak{D}}=+42-45^{\circ}$ $\mathrm{n}_{20}=1.4725$, S.Z. 18.3., E.Z. 27.5, E.Z. nach Actlg. 83.2, löslich in 0.5 vol. $70 \%$ igen alkohols.

Dieses Öl enthaelt: $76.3 \%$ sauerstoffhaltige Stoffe und $23.6 \%$ Terpenkohlenwasserstoffe. 
Mit Hilfe der Dünnschicht und Gaschromatographie wurden im Öl 5 Terpenkohlenwasserstoffe und 13 sauerstoffhaltige Stoffe identifiziert. Diese sind: Camphen (7.1\%), $\alpha$ - Pinen (6.5\%), Limonen $(1.6 \%), \mathrm{p}$ - Cymen $(1.2 \%), \beta$ - Pinen $(0.1 \%)$, und Campher $(30$ $\%)$, Fenchon (18\%), Geranylacetat (6.2\%), Cineol (5.3\%), Terpineol (4.1\%), Bornylacetat (2.4\%), Terpinen-4-ol (2.3\%), Linalylacetat $(1.4 \%)$, Cirronellol (1.2\%), Gerainol (1.1\%), Nerol $(0.8 \%)$, Linalol (0.6\%), Borneol (0.5\%).

Davon wurden Campher, Fenchon und $\alpha$-Pinen isoliert, Zur Identifizierung dieser Stoffen; ihre IR Spektren wurden aufgenommen und ihre Derivate gebildet.

Die quantitative Bestimmung des Öls wurden mit der Methode «Planimetrie» gemacht. Den Hauptbestandteil dieses aetherischen Öls bildet Campher und Fenchon. Linalol und Linalylacetat ist nur in sehr geringen Mengen vorhanden.

\section{T ER A T ÜR}

1 - Boissier, E., - Flora Orientalis Vol. IV Genevae et Basileae (1879).

2 - Arctander, D., - Perfume and Flavor Materials of Natural Origin, Elizabeth. N. J., U.S.A. (1960).

3 - Gildemeister, E., Hoffman, Fr., - Die Aetherischen Öle, Band VII, 4. Auflage, Akademie - Verlag, Berlin (1961).

4 - Amacher, P., - «Preparation and determination of effervescent tablets Containing essential oils» - Pharm, Acta Helv. 40, 345 (1965).

5 - Ehrhart, G., Ruschig, H. - Arzneimittel Band 1, Verlag Cnemie GMBP Weinheim (1968).

6 - Martindale - The Extra Pharmacopoeia, Twenty-sixth ed. The pharmaceutical Press, London (1972).

7 - Rovesti. P., - -Aromatherapy with lavender essential oils» - Riv. Ital Essenze, Profumi, Piante offic., Aromi, saponi, cosmet Aerosol 53, 251 (1971).

8 - Valnet, J., - Aromathérapie 5. édit., Librairie Maloine S. A., Paris (1972).

9 - Öztığ F., - «L. stoechas und L. cariensis Boiss. Eine vergleichend morfologisch - anatomische Untersuchung zweier charakterpflanzen der Türkischen Macchie» - Rev. Fac. sc., Üniv., İstanbul 10/B 251 (1945). 
10 - Tanker, N., - "Gas Liquid Chromatographic Researches on the Volatile Oil of a Thymus Species (T. sipyleus Boiss.) With a Lemon-like Odour.»J. Fac. Pharm. Ankara 3, 115 (1973).

11 - Karlsen, J., Svendsen, A. B., - «Einige Erfahrungen bei der Wahl gepackter Trennsaeulen bei der Gaschomatographie sauerstoffhaltiger Terpene " Die Pharmazie, 10, 613, (1973)

12 - Gildemeister, E., Hoffmann, Fr., - Die Aetherichen Öle, Band II, 4. Auflage, Akademi Verlag, Berlin (1961).

13 - İbid. Band III-c (1961).

14 - Bellanato, J., Hidalgo, A., - Infrared Analysis of Essential Oils, Heyden and Son Ltd., London (1971).

15 - Tanker (Gülen), N., - «Juniperus nana Willd. Bitkisi Üzerinde Farmakognozik Araștırmalar.» - Doktora Tezi, İstanbul (1958).

16 - Carrol, M. F., Price, W. J., - «Routine analysis of essential oils by infrared Spectroscopy» - Perr. and Essen. Oil Record 55, 114 (1964). 